\title{
O sagrado e profano em "O idiota" de Dostoiévski
}

\author{
Julian Nazário
}

Romance predileto de Dostoiévski, $O$ idiota tem como personagem central Míchkin, um príncipe decadente que sofre de epilepsia e está de volta a seu país, após um longo período de convalescença num sanatório europeu. Sua ingenuidade ê tão marcante que as pessoas acabam apelidando-o de "idiota"; todavia, na medida em que a trama evolui, percebe-se que Míchkin não é um mortal comum, mas o símbolo de Cristo Redentor. Dar os fortes traços alegoricos deste romance que trata da salvação da sociedade russa do século XIX, uma sociedade corrompida pelo dinheiro.

Em linhas gerais, a história gira em torno de três personagens: Míchkin, Rogójin e Nastássia. Diametralmente oposto a Míchkin, Rogójin encarna o demônio. Enquanto Míchkin personifica a transparência da alma humana, Rogójin, com seu olhar penetrante e enigmático, transmite uma aura de mistério. Esta disparidade entre as duas personagens se faz sentir desde o primeiro capítulo: “Míchkin é a luminosidade, o espírito bom, o santo, Rogójin, a face má do homem, o criminoso em potencial, aquele que não podia caminhar na luz"(1).

Depois do primeiro encontro com Míchkin, Nastássia apaixona-se por ele mas depois, sem nenhuma explicação, muda de idéia e foge com Rogojin. Este gesto inusitado caracteriza a personalidade desta mulher impetuosa e temperamental que foi seduzida por um homem rico quando mocinha e leva a vida de uma libertina.

De acordo com George Steiner, dentre os romances de Dostoiévski, $O$ idiota é o que prima pela simplicidade formal ${ }^{(2)}$. No entanto, a meu ver, $O$ idiota oculta uma complexidade que apenas se manifesta após uma leitura mais cuidadosa. O livro está repleto de cenas que parecem desconexas, porém, no melhor estilo do romance policial, Dostoiévski deixa pistas espalhadas ao longo da narrativa, amarrando tudo num desfecho impressionante. Aliás, o próprio autor afirmou que "todo o romance foi concebido quase exclusivamente em função de seu desfecho"'(3).

Dada a oposição que se estabelece entre Míchkin e Rogójin, uma análise de $O$ idiota necessariamente teria que levar em consideração a estrutura binária inerente à obra; ou seja, a luta entre duas forças conflitantes. Contudo, esta configuração maniqueísta não solucionaria o problema principal: a mistura de elementos sagrados e profanos. Por esta razão, optei pelo esquema apresentado por Iuri Lotman e Boris Uspenski no ensaio "O modelo binário na dinâmica da cultura russa (atê fins do século XVIII)"(4), que oferece melhores possibilidades para um estudo abrangente.

Na opinião dos dois teóricos, a história da cultura russa até o fim do século XVIII "fornece provas de uma nítida divisão desta cultura em etapas que se substituem entre si num processo dinâmico".

Este modelo delineia a estrutura binária da cultura russa e mostra como os valores culturais (ideológico, político, religioso) da época medieval russa estavam divididos de maneira bipolar, sem levar em consideração classificações axiológicas ou neutras. O resultado desta divisão foi uma disparidade entre as mudanças culturais no Ocidente e na
JULIAN NAZARIO é professor de Literatura Inglesa e Americana da PUC-Săo Paulo. Doutor em Comunicaçăo e Semiótica, com teses sobre Laurence Steme e Lewis Carroll (inéditas).
1 Dostoiévski: ambigüidade e flcç̧ăo, Rodolfo Gomes Pessanha. Rio de Janeiro, Ed. Civilizaçăo Braslleira, p. 48 .

2 Tolstoy or Dostoyevsky, George Steiner. N. York, Alfred A. Knopf, 1959. p. 71 .

3 Dostoiévski artista, Leonid Grossman. Rio de Janeiro, Ed. Civilizaçăo Brasileira, 1967, p. 66.

4 "Binary models in the dynamics of russian culture", luri M. Lotman e Boris A. Uspenski, in The semiotics of russian cultural history, $\mathrm{Vv}$. Aa. N. York, Cornell University Press, 1985. 
Rússia; enquanto as mudanças no Ocidente demonstraram uma certa continuidade, na Rússia elas ocorreram de maneira tão abrupta que o resultado foi "como uma negação radical dos elementos anteriores à mudança" (5). Dar pode-se concluir que, em termos estruturais:

“A nova cultura não proveio de um acervo cultural (...) mas foi o produto da transformação da velha cultura, através de um processo pelo qual esta foi revirada de tal maneira que as repetidas transformações levaram à regeneração de formas arcaicas"(6).

Sem dúvida, na observação deste modelo cultural do passado, o povo exerce uma influência considerável no que se refere à preservação cultural do passado; e, na medida em que a nova Rússia cristianizou-se, o sagrado e o profano coexistiram de tal modo a provocar uma reviravolta do antigo panteão dos deuses pagãos. Será este modelo binário que nos servirá de base para nossa análise.

O livro começa e termina com uma imagem reveladora: Míchkin e Rogojin sentados frente a frente. No primeiro capítulo, os dois se encontram num trem, em vagão de terceira classe; no penúltimo capítulo, o confronto se dá nos aposentos de Rogójin, após o assassinato de Nastássia. Agora, no entanto, eles se encontram sentados em duas cadeiras, os joelhos quase se tocando. Estas imagens esboçam um movimento circular como um indice da mitificação do tempo. Sobretudo, o relacionamento dessas duas personagens realça a ambigüidade dos mundos sagrados e profanos que "não se definem rigorosamente mas são ambos necessários ao desenvolvimento da vida"(7).

Embora Míchkin se destaque como a personagem central, Rogojin aos poucos se transforma de simples concorrente à mão de Nastássia numa presença maléfica que domina todo o romance. Lentamente, ele adquire as feições de um endemoninhado, cujo terrível olhar chega a assustar o príncipe. Ẻ ele que tentará matar Míchkin e que, no final do livro, acaba assassinando Nastássia, o pivô do triângulo amoroso. Porém, não se trata de um simples romance que termina de forma trágica. Ao contrário, $O$ idiota está repleto de referências religiosas que reforçam o tema principal: a salvação da sociedade russa por intermédio de um deus feito homem; no entanto, essas referências religiosas e, por conseguinte, sagradas passam por um processo dessacralizador resultando em símbolos que combinam elementos sagrados e profanos. Esses símbolos, por sua vez, acabam criando situações ambíguas - por exemplo, Míchkin, com sua aura de santo, é sem dúvida uma representação do Salvador, mas mesmo quando ele se esforça para conscientizar as pessoas e convencê-las da falsidade da sociedade, suas tentativas estão fadadas ao fracasso. Insultado, esbofeteado, rejeitado, ele $\epsilon$, na verdade, um salvador incapaz de salvar a si mesmo, e a epilepsia da qual sofre é um sinal desta incapacidade.

Se por um lado Dostoiévski nos presenteia com a figura de um Cristo beatífico, por outro ele cria um anticristo de carne e osso, que vai buscar inspiração no quadro $O$ Cristo morto (do pintor alemão Hans Holbein, 1497-1543). O quadro, que deixa Míchkin transtornado, encontra-se na casa de Rogojin e, portanto, associa-se a esta personagem misteriosa; torna-se claro que a oposição entre essas duas imagens de Cristo (uma sagrada, a outra, profana) é, na realidade, uma metáfora da oposição entre os dois protagonistas. Lembremos que Holbein dessacraliza a figura tradicional do Cristo morto em seu famoso quadro sobre o qual nos é dada a seguinte informação:

"A morte foi um tema com o qual Holbein cedo se familiarizou, na sua procura realista; copiando o cadáver de um afogado no Reno, pintou em 1521 o Cristo morto. Num espaço alongado e baixo, Holbein mostra as formas naturais com surpreendente minúcia anatômica, a provocar um abalo na devoção com a qual este corpo sempre foi velado na arte sacra (...). O tema da morte é tratado aqui com certa irreverência (...)"'(8).

5 Op. cit., pp. 31-3.

6 Op. cit., p. 33.

7 L'homme et le sacré, Roger Caillois. Paris, Éditions Gallimard, 1950, pp. 18-20.

8 Genios da pintura, vol. 9, "Do Maneirismo ao Barroco". Såo Paulo, Ed. Abrit, p. 4.

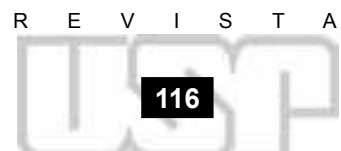

Dezembro

Janeiro

Fevereiro

1990-1991
O Cristo que Rogójin venera é uma figura dionisíaca, cuja presença aponta para o regresso a um passado mítico, caracterizado por rituais selvagens. Aliás, o que não falta são alusões ao passado, principalmente quando Lébedev, uma das personagens, fala diante de um grupo de pessoas sobre as condições socioeconômicas do século XII na Rússia, afirmando que durante este período, quando o povo passava fome, não era incomum ouvir-se falar de casos de antropofagia. Em seguida, conta a história de um sujeito que confessou ter matado e comido 66 monges, além de outras pessoas. Um mem- 
bro do grupo interrompe este relato com a observação de que se poderia explicar a preferência por monges por serem eles as únicas pessoas bem alimentadas do século XII. Salta aos olhos, neste trecho, a ferocidade da crítica social do autor, além do tom satírico; contudo, o tom muda subitamente quando Lébedev, prosseguindo sua história, conta como o antropófago decidiu entregar-se às autoridades. Lébedev se comove com a coragem do homem e, ao terminar o relato, tece elogios a este antepassado que vivia numa época em que a humanidade tinha princípios, virtude nada fácil de se encontrar entre as pessoas de seu tempo.

Na opinião de Lébedev, os homens do século XII eram dotados de mais força de caráter porque nutriam um sonho que os fizera suportar a miséria, a tortura e a doença. Este sonho também os ajudou a viver em harmonia com seus semelhantes. Estas alusōes: a um passado remoto fazem lembrar um perfodo na história da Rússia, quando o cristianismo ainda não havia sido introduzido no país pelos príncipes de Kiev. Antes de ser obrigado a aceitar a nova religião no século X, o povo eslavo adorava deuses pagãos ${ }^{(9)}$.

O fato de o livro começar e terminar praticamente com a mesma imagem - Míchkin e Rogojin face a face - reforça ainda mais a referência a um ciclo temporal mítico, e para melhor entender o significado desta referência, é preciso examinar com mais detalhes o penúltimo capítulo, onde se localiza o clímax do romance.

A organização deste capítulo deixa transparecer a preocupação do autor em provocar um forte impacto sobre o leitor, tanto do ponto de vista emocional como artístico. E tudo leva a crer que Dostoiévski conseguiu isso, nesse trecho estarrecedor. Uma grande quantidade de signos fazem parte deste capítulo de contornos nitidamente formais. O próprio autor parece mudar de estilo quando traz Rogojin para o primeiro plano da narrativa - um lugar até agora reservado a Míchkin. Colocando os dois protagonistas em confronto, Dostoiévski deixa-os dialogar e movimentar-se em cena livremente.

O capítulo começa com Míchkin à procura de Nastássia em Petersburgo, depois que esta foge com Rogojin, sem cumprir a promessa de casamento com o príncipe. Primeiro, Míchkin vai à casa de Rogójin. A empregada o informa que não há ninguém no apartamento. Desconfiado, Míchkin põe-se a rondar o prédio, certo de que os dois estão lá dentro. Imagina que vê alguém na janela do quarto de Rogбjin, um vulto que espreita por trás das cortinas cerradas. Dirige-se, então, à casa onde Nastássia se hospedara. Ela não está, mas, mesmo assim, Míchkin penetra nos aposentos da casa e encontra um livro em cima da mesa da sala. Este livro, Madame Bovary, sugere uma possível ligação entre a morte de Nastássia e Emma Bovary, ambas vítimas de uma sociedade burguesa. Míchkin fica sabendo que Rogojin e Nastássia costumavam jogar cartas quando esta se sentia entediada; por isso ele faz questão de apoderar-se do baralho que eles utilizavam. Pode-se aventar a hipótese de que nesse trecho haja uma sutil alusão a um jogo incessante entre Míchkin e Rogojin, o qual teria como prêmio maior Nastássia - um jogo, aliás, que o príncipe acaba perdendo.

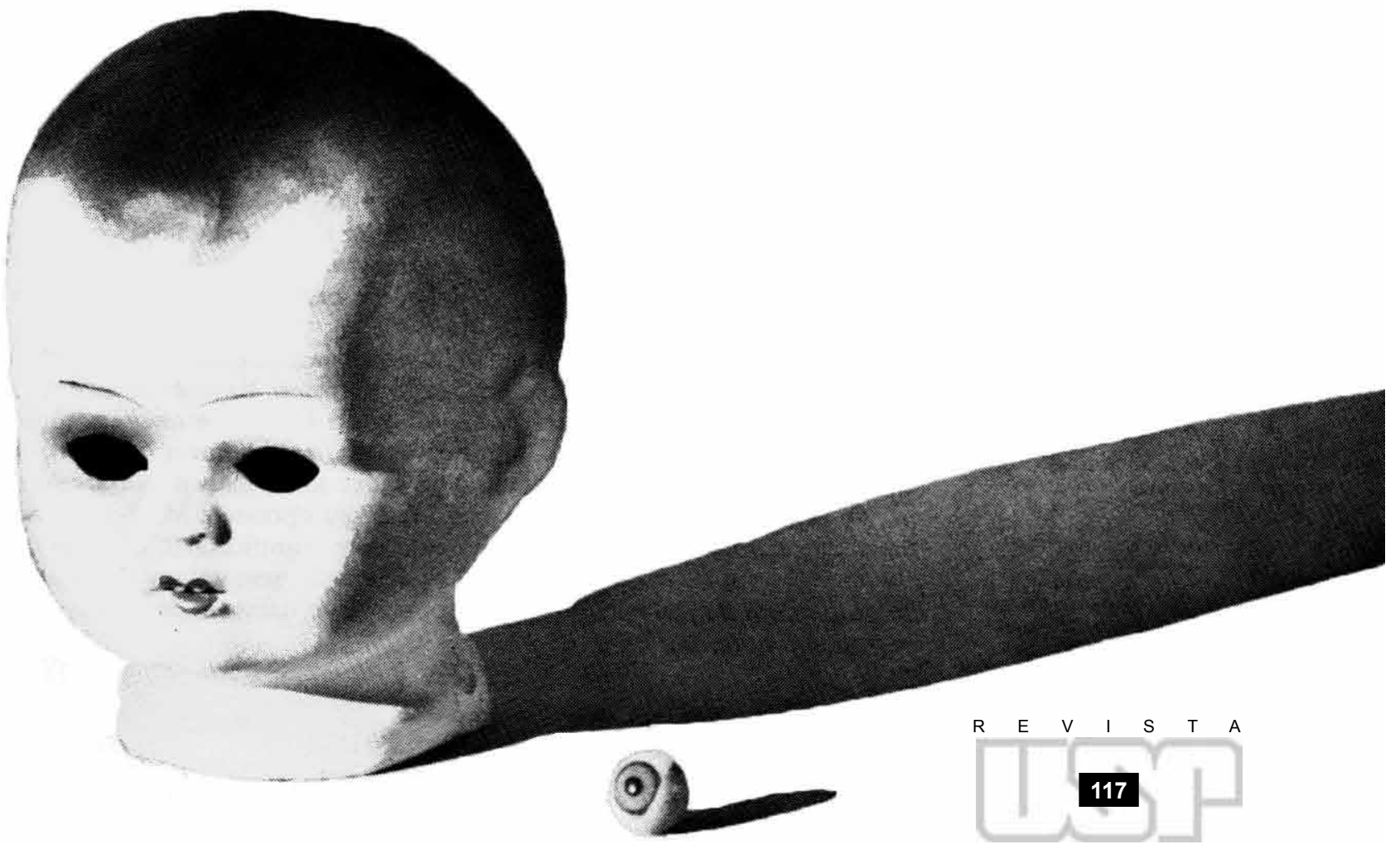


Depois de sair da casa de Nastássia, Míchkin vagueia pelas ruas de Petersburgo, quando $\varepsilon$, de repente, abordado por Rogojin que surge do meio da multidão. Rogójin pede a Míchkin para acompanhá-lo e, a caminho de sua casa, age de modo estranho: dá instruçōes a Míchkin para continuar andando, enquanto ele, Rogojin, seguirá pela calçada, do outro lado da rua. Parece que Dostoiévski procura enfatizar aqui os dois pólos que Míchkin e Rogójin representam, a fim de transformá-los em símbolos vivos de duas correntes opostas. O que mais impressiona neste capítulo são as cenas no quarto de Rogójin, local da morte de Nastássia, onde reina um silêncio mortal. Este silêncio cria um clima mórbido que vai se tornando cada vez mais opressivo, à medida que Míchkin e Rogojin passam a sussurrar, a fim de não "acordar" a mulher que dorme o sono eterno. Como que para reforçar a impressão de alguém que dorme, surge a referência a "sònho" em "um sonho de imobilidade total". Nesta cena sobressai o branco: as cortinas do quarto, o vestido que Nastássia usou antes de morrer, o lençol que cobre o corpo estendido na cama, tudo é branco. Dostoiévski faz questão de ressaltar neste trecho o fenômeno das noites brancas que caracteriza a cidade de Petersburgo:

"Não havia iluminação no quarto; as noites brancas de Petersburgo começavam a escurecer e, quando não havia lua cheia, o quarto mergulhava na escuridão"(10).

A lua cheia, que está sendo esperada no céu, é mais um dado da loucura que se apossará de Míchkin e Rogójin quando o romance termina, e a cena é apresentada de tal maneira que a impressão final é a de um velório. Por sua vez, a morte de Nastássia não deixa de remeter a um ritual praticado nos limites de um espaço sagrado: a cama, onde jaz o corpo, está separada do resto do quarto por uma cortina verde. Por baixo do lençol branco que a cobre, Nastássia está totalmente despida.

As cenas impressionam pelo clima macabro: Míchkin e Rogojin conversam como se nada de extraordinário houvesse acontecido, e a sensação de algo estranho se intensifica quando ambos começam a discutir, com frieza, sobre o assassinato, à maneira de dois médicos numa aula de anatomia. Além do mais, Rogojin faz questão de frisar que cobriu o corpo com "um bom pedaço de couro americano" e colocou quatro jarros de desinfetante em volta da cama para combater o mau cheiro da decomposição. Torna-se claro que Dostoiévski está preparando o leitor para o momento crucial, quando os dois enlouquecem deitados sobre a cama que Rogojin improvisou ao lado do corpo de Nastássia. Em face disso tudo, a morte de Nastássia seria vista como um rito sacrificial, uma oferenda aos deuses, com o objetivo de desencadear um processo que traria de volta, por assim dizer, os tempos áureos da Idade de Ouro russa. Os índices ritualistas nos permitem ver em Nastássia um vigoroso símbolo da Terra Mãe, cujas origens têm raízes no mito grego de "Gaia", a deusa cósmica primordial.

Etimologicamente, a palavra géia prende-se a húmus (terra): "em todas as culturas sempre houve 'enterros' simbólicos, análogos às imersōes batismais, seja com a finalidade de fortalecer as energias ou curar, seja como ritos de iniciação. De toda forma, esses regressus ad uterum, essa descida ao útero da terra tem sempre o mesmo significado religioso: a regeneração pelo contato com as energias telúricas; morrer para uma forma de vida, a fim de renascer para uma vida nova e fecunda"(11). Tendo em vista esses dados, é bem possível que a cor verde da cortina no quarto de Nastássia seja um símbolo de regeneração da esperança.

O último capítulo do romance se intitula "Conclusão" e termina com as palavras da senhora Epantchiná, uma espécie de mãe adotiva de Míchkin, que o visita num asilo depois que ele enlouquece. Na opinião da senhora Epantchiná, a Europa "é uma fantasia, como são fantasias todas as pessoas que vão para o estrangeiro". Estas palavras se revestem de uma forte carga nacionalista e o problema do nacionalismo está muito presente no romance.

Aliás, o que se nota $e ́$ que a personalidade marcante de Rogojin provoca uma mudança do ponto de vista ideológico no fim do romance. Exercendo a função de personagem secundária, sua pesença se impóe de tal modo agora que chega a suplantar a de Míchkin. Assim, neste penúltimo capítulo, Rogojin, esse homem do povo, cuja fala cheia de erros reflete a classe social à qual pertence, se torna mais importante e se investe do papel de protagonista principal; ao passo que seu oponente Míchkin, o nobre, fica relegado a um plano secundário. Fato extremamente significativo, à medida que revela como Dostoiévski foi se empolgando com esta personagem enigmática que, além de assumir as proporções de um ser sobre-humano, sobressai também como modelo da exaltação do sentimento nacional. 